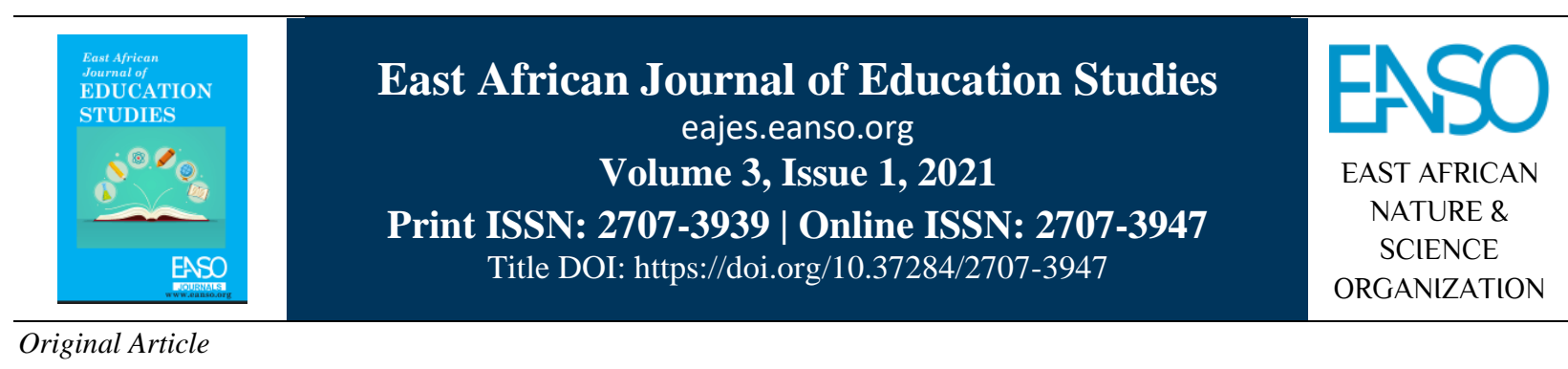

\title{
Economy, Education and Physical Education in Kenya in the Light of Statistical Indicators.
}

\author{
Dr. Gabriella Hideg, $P h D^{* 1}$ \\ 1* Senior Lecturer, University of Pécs. \\ *Correspondence Email: gabriella.hideg@etk.pte.hu.
}

Article DOI: https://doi.org/10.37284/eajes.3.1.415

\section{Date Published: ABSTRACT}

17 September 2021 Kenya was once a British colony, and today it is a fast-growing country with world-class hotels and shopping malls on one side of the road, while misery and

Keywords: poverty show their cruel faces on the other side. It is a country where internal struggles and political unrest are ongoing, corruption is enormous, and an

Economy, increasing number of terrorist organizations are appearing (even breaking into

Education, universities and slaughtering young people for their religious affiliation). The

Physical Education, aim of our work is to present the economic, social, and socio-cultural Kenya background of the country. We considered it important to highlight economic indicators such as the proportion of GDP spent on education at each level of the education system, alone and compared to other countries, and we also examined the population pyramid of the country. One of the interesting points of the study is the comparison of Kenya's educational values with those of Malaysia or Africa, and also specifically mapping the physical education development of Kenya. In the course of our research, we relied on the available literature and the analysis of statistical data, however, personal experiences and observations are interspersed with the study. As a result of our work, we can get a clearer picture of the economic, social, and socio-cultural environment of a wonderful country, thus bringing the values of a distant world closer.

\section{APA CITATION}

Hideg, G. (2021). Economy, Education and Physical Education in Kenya in the Light of Statistical Indicators. East African Journal of Education Studies, 3(1), 253-262. https://doi.org/10.37284/eajes.3.1.415.

\section{CHICAGO CITATION}

Hideg, Gabriella. 2021. "Economy, Education and Physical Education in Kenya in the Light of Statistical Indicators". East African Journal of Education Studies 3 (1), 253-262. https://doi.org/10.37284/eajes.3.1.415. 
East African Journal of Education Studies, Volume 3, Issue 1, 2021

Article DOI: https://doi.org/10.37284/eajes.3.1.415

HARVARD CITATION

Hideg, G. (2021) "Economy, Education and Physical Education in Kenya in the Light of Statistical Indicators", East African Journal of Education Studies, 3(1), pp. 253-262. doi: 10.37284/eajes.3.1.415.

\section{IEEE CITATION}

G. Hideg, "Economy, Education and Physical Education in Kenya in the Light of Statistical Indicators", EAJES, vol. 3, no. 1, pp. 253-262, Sep. 2021.

\section{MLA CITATION}

Hideg, Gabriella. "Economy, Education and Physical Education in Kenya in the Light of Statistical Indicators". East African Journal of Education Studies, Vol. 3, no. 1, Sep. 2021, pp. 253-262, doi:10.37284/eajes.3.1.415.

\section{INTRODUCTION}

The social structure of Kenya's population of about 47 million shows a very diverse picture. This is partly due to ethnic diversity, as Kenya's society is based on forty tribes, which means that many tribal communities still live together to this day, in addition to the fact that other European ethnic groups live in the area. On the other hand, we must also take into account religious differences, as in addition to the religions we know and are present in Europe (Catholic, Protestant, Islamic, etc.), the different tribal religions also colour the social composition. Thirdly, we must also mention the high number of refugees received by Kenya. Of Somali refugees alone, about 400,000 live in Kenya (CIA World Factbook).

In terms of age composition, Kenya is one of the typical African states. (Figure 1) The majority of the population (more than $40 \%$ ) consists of children under 15 years of age. The average life expectancy at birth is only 65 years, and accordingly, the elderly people make up only $3 \%$ of the population.

Figure 1: Age structure diagram of Kenya based on 2021 data (CIA World Factbook)

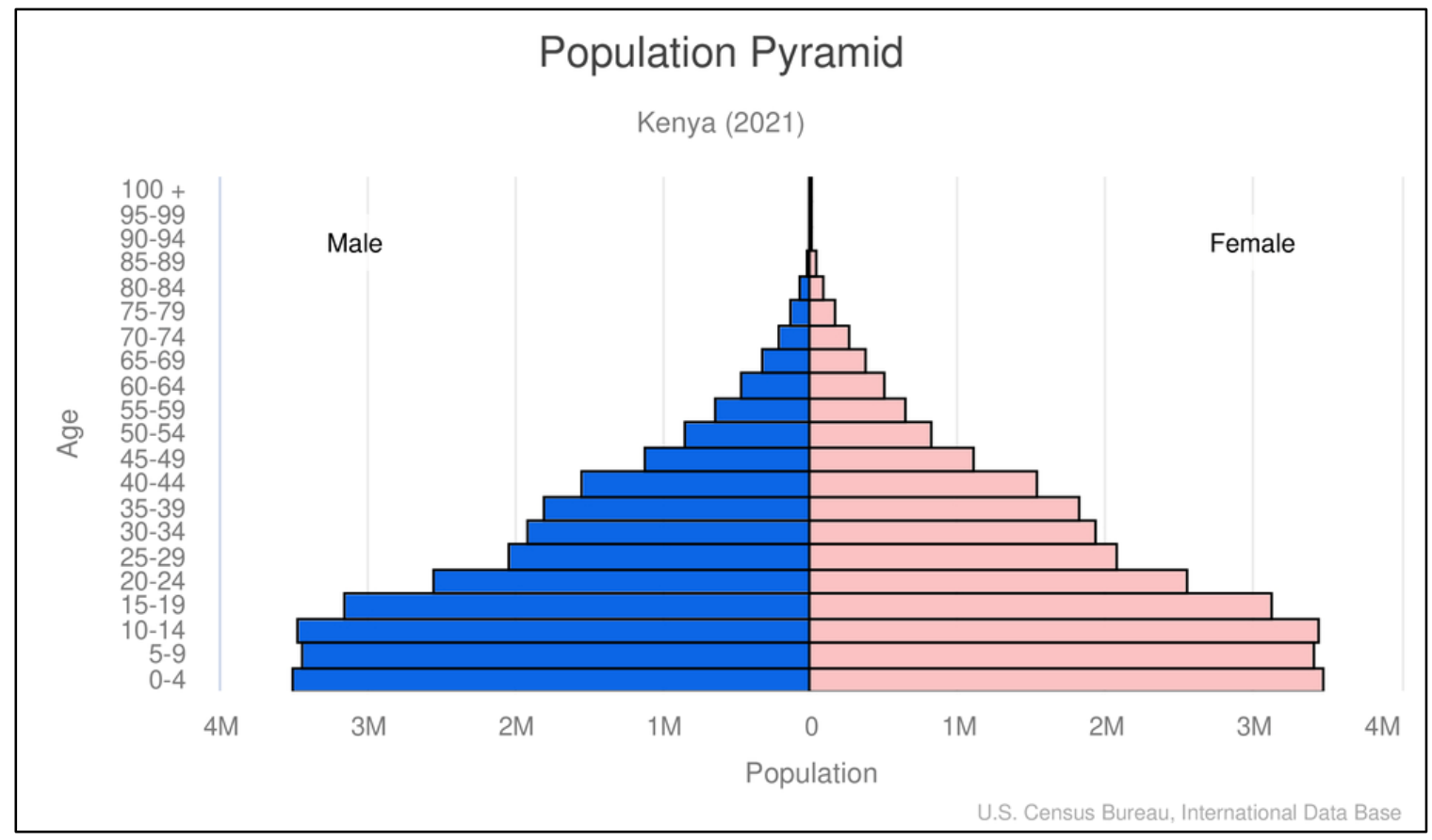

\section{Kenya's Expenditure on Education}

Although statistics show that about $80 \%$ of Kenyans can read and write, children attend school until they are 11 years old on average. This is due to the still high child mortality rate compared to Europe, the deaths due to AIDS, and the early marriage of girls. To prevent this, the Kenyan government spends a relatively large amount on financing health care, 
about $5.7 \%$ of its annual GDP, making it ranked 148th in the world (World Bank database).

On the one hand, we consider it important to highlight the tribal tradition according to which children living in the countryside must leave school very early to participate in tribal production. On the other hand, parents have to decide whether they would like to send their child to school as it will incur expenses, and an earner will be left out of the family. This can be a strange situation for
Europeans, with 16 to 18-year-olds often attending the same class as children aged 10 to 12 . We emphasize, this is not because they are repeaters, but because their parents could no longer fund their otherwise free primary education.

If we are talking about education, it is worth looking at the GDP-proportionate spending on education in Kenya as a developing country - we will also do the same for the other countries studied - according to the UNESCO database (Figure 2).

Figure 2: Kenya's expenditure on education as a share of GDP 1999-2018

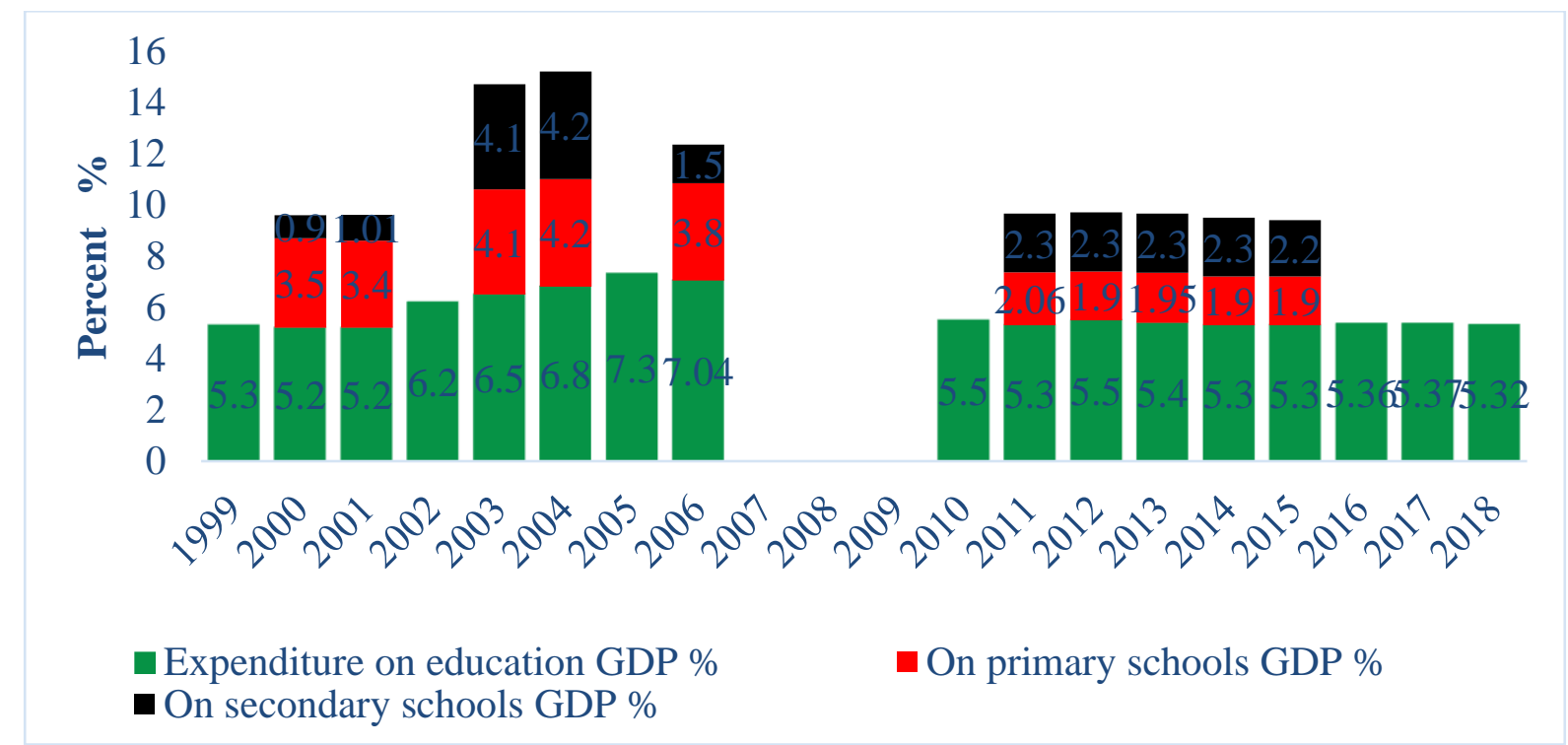

Source: UNESCO Institute for Statistics (2020) (Own editing)

Our figure illustrates total spending on education and spending on primary and secondary schools as a proportion of GDP. It can be seen that the Kenyan government's spending on education increased between 1999 and 2005 but has declined significantly since 2010 . The Kenyan state spends $5.32 \%$ of GDP on education, according to 2018 data.

Money spent on primary schools has almost halved since 2010, while money spent on secondary schools has doubled. In the background of this, the global economic crisis may be just like the ongoing internal political struggles in Kenya, but we also cannot ignore the government measures that emphasize and support different levels of the education system in almost every election cycle. By comparison, of the developed countries, the UK, which has good relations with Kenya, also spends an average of $5 \%$ on education development. And if we look at another developing African country, we can see that the average in neighbouring Sudan is only $2 \%$ (World Bank database).

If we further analyse the GDP data, it is also worthwhile to study the economic indicators of Kenya, as the development of the economy greatly influences the amount that can be spent on sports. According to the World Bank, Kenya's GDP growth was significant after the global economic crisis of 2008, then the increase until 2010 is characterized by a currently stable annual growth of 2-3\% after a small decline (World Bank database).

With this growth rate and an annual GDP of 3400 USD/capita, Kenya ranks 185 th in the countries 'GDP rankings. Among the main causes of the 
country's poverty are the exceptionally high unemployment rate (almost 40\%), the fact that about a third of industrial production is still made up of the agricultural sector, and accordingly, $80 \%$ of the country's population works in agriculture. In addition, corruption is very high, and the inflation rate exceeds $6 \%$ per year, which means that the general government deficit is also growing year by year. It is reassuring that tourism in Kenya appears to be booming, which also favours infrastructure investment. ${ }^{4}$

This GDP growth can be a good basis for development, but the extent of corruption in the country should not be overlooked. Corruption in Kenya poses the greatest threat to the functioning of the judiciary, police, and government offices. These areas have the highest levels of corruption, with perpetrators being held accountable only in the rarest of cases. When examining the extent of corruption, it can be concluded that the corruption situation in Kenya can be a deterrent to foreign investors. It is common practice for 6 out of 10 companies to use bribery, extortion, and blackmail in business. For Kenya to truly develop, it is absolutely necessary to push the level of corruption back. This is true not only for business but also for the civil sphere, where human rights are still rarely taken into account and freedom of the press is only partially realized (Anti-corruption portal). In the latter area, the government must take action. It is important to mention that curbing corruption is also key because Kenya is a priority target area of support for the European Union (about EUR 435 million was voted for the country in the 2014-2020 cycle alone!) (International Cooperation and Development of EU), the World Bank Group and the IMF (IBRD), who sacrifice money for economic development.

\section{The Development of Physical Culture in Africa: Special Reference to Kenya}

Kenya, like Malaysia, was a British colony, and as a result, many similar features can be observed in the presentation of their physical culture development. The society of the African country was initially built on nearly 40 tribes. This tribal society had its own physical culture, which was primarily limited to subsistence. Even today, there are still tribes in Kenya that preserve traditions, such as a boy becoming a man and a full member of the tribe when he hunts down a lion. Jones (1924) found that among the sporting activities traditionally practiced, there is a significant number of those that humiliate the body, soul, and spirit. And these must be eliminated, suppressed, and a way must be given to the achievements of Western civilization, including sporting activities. According to Scriven (1973), in Kenya, like Malaysia, sport played a prominent role in national unification. Carrying out sporting activities helped the cultural integration of Western ideas and practices. Given the significant increase in the number of nationalities as a result of colonization, the sport was a common language. Football is perhaps one of the best examples of this, enjoyed and played by everyone, regardless of ethnic, social, cultural background, or education. On the field, during the game, everyone was considered equal.

The period of colonization also played an important, breakthrough role in the formation of Kenyan sports organizations. In the 1920s, the first British-style sports organizations were formed, such as the Kenya Amateur Athletic Association, the role of which was to embrace and support the amateur sport. This was followed in 1952 by the formation of the Commonwealth Games Association and in 1954 by the establishment of the Kenya Olympic Association. As a follow-up to the establishment of sports organizations, the government has entrusted local organizations (municipalities) with the task of developing community sports. Later, districts and regions were formed, and a network of officials was built for governance. (Nteere, 1991)

Following the liberation, the existing structure was reorganized, and the field of sports was built on three pillars. The Kenya Olympic Association's task is to arouse interest in amateur sports, promote participation in the Olympic Games and other international competitions, and strengthen the goals of the Olympic movement in Africa and Kenya. The aim was also to maintain contact with the International Olympic Association, as well as to promote smooth communication with the Allies. For all of these, it also had to provide the financial background. The second pillar is the Government Department of Sports and the third is the Kenya National Sports Council, which was established in January 1966. Its job is to provide community 
development and social services. To this end, the Ministry of Labour and Social Services has also been involved in the work of the organization. The primary goal is to promote sports and recreational activities among the population, thereby increasing overall well-being and health. (Nteere, 1991)

Despite government measures, which have apparently boosted the employment of civil servants, the boom in Kenyan sports has been brought about by the fact that, on the one hand, the possibility of breaking out of poverty has been accompanied by an athlete's career, and on the other hand, independently organized sports clubs were established, where after-school activities were organized for young people. We would like to note here that although physical education was compulsory in both primary and secondary education, it was not implemented due to a lack of teachers and infrastructure. In addition, the Ministry of Education did not build an examination system for the subject, thus, students were not even tested.

It is also important that the above-mentioned limitations persist to this day, and there is even a perception that physical education takes valuable time away from other "useful, important" subjects (e.g., mathematics, writing, reading, English language).

In Kenya, the sport is as old as history, part of the ancient tribal culture and a traditional ancient sport such as wrestling, bullfighting, or even hunting still appears within the tribal framework. Football and athletics were the first sports to appear in schools. In the post-colonization era, much less emphasis was placed on physical education. Although compulsory physical education was introduced when the education system was revised in 1988, physical education was not taken seriously until the 2000s, when private schools appeared. The emergence of private schools has significantly promoted good relationships between children and coaches as well as parents, resulting in an increasing number of athlete school students. In addition, it is also a problem that in Kenya, as in other developing countries, the number of obese people has started to increase in parallel with the process of urbanization. The 30-40 minutes of exercise per week required by the state in general and public education does not help this either, partly because it is not enough and partly because children are not motivated to move beyond this basic level. There is also a negative effect on the mood of sports among girls/young women due to the mandatory clothing requirement due to religion, which in many cases makes them unfit to engage in any sporting activity, so they are already at a disadvantage in sports education compared to boys. We should also mention here the lack of infrastructure, as there is no adequate place or material conditions for conducting physical education classes in public schools. In private schools, of course, there are many more opportunities for students to play sports, swim, exercise, do athletics, but private schools make up only $16 \%$ of the institutions, so few students have access to the aforementioned sporting opportunities (Mwisukha and Rintaugu, 2012).

Today, Kenya has many popular sports. These are mainly athletics, rugby, football, volleyball, basketball, but also motorsports, tennis, and golf. Of course, Kenyan athletes are best known to the world for their achievements in long-distance running, as it is enough to mention the various marathons, where a Kenyan athlete takes the lead. But they also achieved nice success in rugby, and the women's volleyball team also sparked its talent, although so far, they have achieved results in the African competition (Sports in Kenya).

Perhaps the best way to compare the sporting successes of different countries is to look at their Olympic performance. Of course, we looked at the results of the summer games, where the medal table shows that the Kenyan team was the most successful at the 2016 games in Rio de Janeiro with 6 gold medals, 7 silver medals, and 1 bronze medal. The Kenya Olympic Committee was formed in 1955 and the team won the first medal at the 1964 Tokyo Olympics. The sports that bring medals, as discussed above, are not surprisingly athletic running and boxing (International Olympic Committee).

It has already been mentioned that many forms of sport are very popular in Kenya, so the state has begun to provide an organized framework for sport, not only by setting up the Olympic Committee but also by setting up the Kenya National Sports Council in 1966. With the establishment of these organizations, the government's main goal was to 
develop sports, focusing mainly on athletics and running. It did this because it recognized that with outstanding sporting successes, not only the athlete but also the nation could gain foreign recognition, and the achievements would attract more and more members of communities to sports clubs to play sports and thus promote their healthy physical development. In a tribal society like Kenya, sport also plays an important role because mass sports can bring different ethnic groups closer together, thus promoting national awareness and the social integration of different tribes. At the same time, there are serious problems behind this noble intention. As Mwishuka and Mukolwe (2007) mention in their study, the representation of Kenyan sports still has a myriad of tasks if it would like to perform its activities effectively. As they write, the minor bad thing is that few have heard of the National Sports Council, but the serious problem is that they have not been able to achieve or present results in controversial cases and representation. Researchers are also making suggestions for solutions in the study, including calling for the placement of professionals who also understand the sport and have a sporting background. They point out that the general problem is the underrepresentation of women among athletes, the lack of state support that athletes receive, as a result of which many talented athletes prefer to move to another state, acquire citizenship there because their athletic careers are financially supported by other countries. For the country to host international sporting events, it is necessary to develop not only the infrastructure but also the sports facilities, which also require financial resources. In addition, it is mentioned that a special program is needed for youth training and sports education, with which the possibility of playing sports can be reached by the widest possible strata and talented children can get a suitable opportunity. We consider it important to emphasize once again that young people do not receive an adequate level of physical education within the framework of school education, partly due to the lack of material conditions. Regardless, they love to play sports and they consider sport as an opportunity to break out of poverty.

Based on the data and knowledge described above, we can conclude that Kenya has a millennial tradition in the field of sports, which can be a great starting point to become a sporting nation. It can be seen that not only in athletics but also in team sports, the country has opportunities to exploit. Considering that the population in Kenya is growing, sporting reinforcements could also be ensured. At the same time, poverty is a serious obstacle to the development of sport in the country. As long as a third of the population lives below the poverty line, there is high unemployment and child mortality rate, high HIV/AIDS rate, and as long as clean drinking water is not provided to the population as a whole, there are much more serious problems for the government to solve than the promotion of the sport. At the same time, development and education have to start somewhere and sport is an area where people can be educated from childhood about the importance of physical activity and its role in maintaining health. Not to mention that it would be economically worthwhile to increase spending on sports, as infrastructure developments are a worthwhile investment when tourism booms as a result of a sporting event. Promoting sports is also promoting the country through the results achieved.

\section{EDUCATIONAL VALUES OF MALAYSIA AND KENYA}

Our work focuses on Kenya, its economic, social, and socio-cultural background. We find it interesting to compare Kenya's educational values with Malaysia as a perspective. Here we want to talk mainly about values, their role in the education system and society. For this, we use official material from the Malaysian Ministry of Education (Malaysia Education Blueprint, 2013-2035) and a study by Rahman (2014).

The Malaysian implications of the 2009 Pisa results have drawn the government's attention to problems in the education system. In addition, parents and the labour market also sounded the alarm due to the unpreparedness and morale of young people leaving the education system. By 2011, management had launched an investigation into a full review of the education system. Experts from all relevant fields were involved in the study, who collaborated with experts from the World Bank, OECD, and UNESCO, relevant experts from six local universities, and they even launched a social debate. Parents, teachers, and children were also asked. The aim was to develop a national education plan that 
prepares young people for the challenges of the XXI. century, while being in line with Malaysian cultural norms, historical traditions, parental and educational policy expectations.

In Malaysia, three nationalities live together (Malays, Chinese, Indians), and as a result, a different culture can cause tension in society in countless areas to this day. The task of the education system, according to the Ministry of Education (MOE), is to develop a common national identity. The future of a country is determined by how society treats its youth. The extent and quality of knowledge passed on to young people currently sitting at their school desks play a role in the economic development of the country. Education is an opportunity to build national unity by helping to understand and transfer knowledge about people from different socio-economic, religious, and ethnic backgrounds, to develop common experiences, and to work together.

Rahman (2014) draws attention to the need for change in the education system. According to his approach, the immeasurable corruption, violence, and greed prevalent in Malay society, which is a natural corollary of political power, senior management, businesses, has been present and make people miserable since the XX. century. It was expected that all of this would have an impact on the value perceptions of rising generations. In 2003, Arthur (2003) also mentions in his study that "moral panic" prevails in society due to the destructive behaviour and moral deterioration of young people. The transmission and teaching of values and the importance of this are not only the task of families, but the education system must also place much greater emphasis on this. In Malaysian society, the teaching of values, according to Robb (1998), means that young people make clear and unambiguous through their behaviour what is and what is not valuable to them. Meanwhile, they evaluate their behaviour based on feedback from the environment, and although they recognize the need for change if they do not see it as "rewarding" for their well-being, in the long run, they do not change it. It is the task of the education system and the educator to emotionally sensitize young people, to develop the need, the desire for the better. For this, it is essential to present and introduce the values to the children and teenagers, based on which the positive values are incorporated into the behaviour through practice. The Blueprint sets out goals such as educating "value-oriented Malays", but this requires transforming existing values. Elements of this include strengthening Islamic education, moral education, and civic elements, increasing volunteering, and introducing young people from different religious backgrounds to other religions.

We agree with Rahman's (2014) statement that there is no tool and system of tools that can guarantee the restoration of values in a short time, but the problem has been identified, a plan for change has been made, however, generations need to grow up before a serious and tangible change takes place. Kenya's resemblance to Malaysia lies in the emergence of value orientation and its prominent role in the education system in recent years. This is due to the shocking experience that young people of school age have poor knowledge and attitudes about values and ethics and their practical application is neglected. Examining deeper social reasons, we can come to similar conclusions as in the case of Malaysia. There is a "tradition" of corruption in Kenyan society. If we look at the wider social aspect, crime and terrorist acts show a negative picture, especially because they go unpunished, as do the corrupt practices of state leaders. From this approach, the behaviour of young people in school - often coupled with aggression, violence, abuse, and its impunity - is not surprising, nor is the loss of value. The tension in Kenya's education system is also fuelled by inequality, which can give rise to understandable tempers. The task of the education system would be to eliminate inequalities. There is little research on the values in the Kenyan literature.

In their book, Agumba et al. (2009) present Kenya's National Educational Goals. In this sense, they formulate eight basic goals, which are the following:

\section{- Promoting nationalism and patriotism and promoting national unity}

Given that Kenya is a diverse nation - a society based on forty-two tribes - the task of education is to ensure that young people are able to see themselves as members of a nation called Kenya, be patriotic to their nation and be willing to serve the nation to contribute to its development regardless of ethnicity. 
- Promoting social, economic, technological, and industrial needs for the development of the nation

The goal and task of the Kenyan education system are to prepare young people for the challenges of a rapidly changing globalizing world. The future of the nation depends on the young people of the country, they need to be taught so that they can utilize the knowledge and skills that are needed in the labour market. The development of the world is increasingly driven by the development of technology, so Kenya has no choice but to prepare its young people for the industrial and technological world in the context of national development. Here we would like to note that all this change is not the first time in the history of Kenya. With the advent of the colonial system (1800s), the former tribal society had to disintegrate and identify with a completely new form of social arrangement.

\section{- Helping the individual development and self- fulfilment}

The range of training offered by the education system should enable young people to find an area in which they can excel, which matches their abilities.

\section{- Helping the solid moral and religious values}

Education is expected to provide knowledge and, at the same time, to promote the moral development of the individual, as only this can lead to the acquisition of desired and expected social values. It is a basic expectation that the individual learns the difference between good and bad. However, we would like to note that this cannot be achieved alone, without the help and practical guidance of a pedagogue, and we also consider the role of the direct social actors and role models presented earlier to be important.

\section{- Promoting social equality and responsibility}

The Kenyan government is working to promote social equality through education. Access to this education is guaranteed to all its citizens, regardless of gender, race, or social background. In practice, however, this is not the case, as not all young people have access to free primary education, given that the financial situation of Kenyan families does not allow this, and they even have to take into account that a breadwinner could fall out of the family if the child is sent to school.

- Respect and promote the development of Kenya's rich and diverse culture

The education system must take into account Kenya's cultural diversity, and young people must be taught to respect and nurture cultural values. Education should seek to be respectful and tolerant of members of other cultures but members of Kenyan society.

\section{- Promoting international self-awareness and a positive attitude towards other nations}

Young people need to understand that they have a responsibility to maintain good relations with their country's neighbours.

\section{- Promoting a positive attitude towards good} health and the environment

Young people need to be aware that the development of a nation depends on healthy citizens, so they have a responsibility for their own health and to secure, preserve and protect their environment for themselves and future generations.

In her study, Wamahiu (2015) details that in 2010 the government adopted a new constitution, in line with which in 2013 it created a so-called Education Program, which formulates guidelines such as the right to basic education or the principles of inclusion, equality, equity, or the elimination of tribal, religious, ethnic-based hate speech. Later, also in her study, Wamahiu (2017) presents the results of research on values conducted by the Ministry of Education (National Value-Based Study, 2014-2015). The study involved more than 10,000 students, representing nearly 1,500 schools, representing $5 \%$ of all schools. In the theoretical framework of the study, it was recognized that children live under different influences, among which there are opposites. The role of school and community was also recognized and the role of religious institutions and the family in value orientation was articulated. The transfer of values is school- and teacher-dependent, thanks to the diversity of the curriculum. There is a formal curriculum, but it is not compulsory to teach it, and 
there is a hidden curriculum that seeks a balance between compulsory, planned, and taught material. Accordingly, there are schools where value-related education takes place, somewhere only partially and somewhere not at all. Respect, tolerance, equality, and peace, which need to be communicated to young people at all levels of the education system, have been identified as core values.

The research also highlighted that the incorporation of these values into the curriculum was neither uniform nor have a satisfactory pace, nor did they recognize the relationship between the different values, which would make their teaching much more effective. The survey also demonstrated that educators appear as models. Young people learned to respect others when they saw it from the teacher as well. If the teacher was late, he talked to the kids rudely, they modeled it. Not surprisingly, teachers who showed child-friendly behaviour were the most popular.

More than half of the values conveyed were about Christian, Islamic, or Hindu values, and only one was true of all four religions. This means, therefore, that the values were very divisive, as children of different religions could hardly find a uniform value system. All this leads to conflicts in the lessons, which the teacher may not be able to take on later.

Overall, as a result of the national survey, it can be concluded that equal opportunities are not achieved within schools, and children are physically and psychologically excluded from classroom activities, which leads to a deterioration in learning outcomes. Tolerance is a core value that is less visible in schools, whether it is a public or church or perhaps a private school. In schools, in addition to the values set out in the constitution, the values of autonomy, responsibility, and unity are paramount. Values such as respect, respect for human rights, or the choice of tolerance were missing from the responses.

\section{REFERENCES}

Anti-corruption $\quad$ portal, Kenya. http://www.business-anticorruption.com/country-profiles/kenya (downloaded: 23.05.2021)
Arthur, J. (2003). Education with Character: The Moral Economy of Schooling. London, Routledge.

CIA World Factbook - Kenya, Source: https://www.cia.gov/the- world factbook/countr ies/kenya/ (downloaded: 13.05.2021)

IBRD website, Kenya, Source: http://www.worldbank.org/en/country/kenya/ov erview (downloaded: 23.05.2021)

International Cooperation and Development of EU, Source: https://ec.europa.eu/europeaid/countrie s/kenya_en (downloaded: 23.05.2021)

Jones, T. J. (1925). Education in East Africa. London: Edinburgh House Press.

Mwishuka, A.- Mukolwe, N. (2012): Strategy for promoting sport in Kenya. Journal of education research and development, 2(1) pp. 142-147.

Mwisukha, A., Rintaugu, E., Kamenju, J., \& Mwangi, P. (2012). Shaping the future of physical education in Kenya. Ming-Kai, C.Edginton, CR (eds): Physical Education and Health Global Perpectives and Best Practice, Nairobi, Kenyatta, University, 270-278.

Nteere, J. S. (1991). The structure and Organization of sport in Kenya and Malawi" in Sports for All into the 90s ISCPES" volume 7, Meyer \& Mayer Verlag, Aachen Germany, 1991.

Rahman, A. (2014): Values Education and the Malaysia Education Blueprint. Journal of Interdisciplinary Research in Education (JIRE), 4(1) pp. 59-73.

Robb, W. (1998): What is values education- And so what? The Journal of Values Education, 1(1) pp. $1-13$

Scriven, F. B. (1973). Sports Facilities for Schools in Developing Countries. An Inventory of Experience and Proposals for Future Projects. Educational Studies and Documents No. 8.

Sports in Kenya. http://www.kenemb.ru/en/aboutkenya/sports.html (downloaded: 20.03.2021) 
Wamahiu, S. (2015). Value-based education in Kenya: An exploration of meanings and practices. Republic of Kenya, Ministry of Education, Science and Technology

Wamahiu, S. (2017). Value Based Education in Kenya: An Exploration of Meanings and Practices.

International Olympic Committee Kenya. (year). Retrieved on May $18 \quad 2021$ from https://www.olympic.org/kenya

World Bank. (2021). GDP per capita growth (annual \%). Retrieved om May 18, 2021 from http://data.worldbank.org/indicator/NY.GDP.P CAP.KD.ZG?locations $=\mathrm{KE}$

UNESCO Institute for Statistics (2020). Government expenditure on education, total (\% of GDP) - Kenya, Sudan. Retrieved May 23, 2021 from https://data.worldbank.org/indicator /SE.XPD.TOTL.GD.ZS?locations=KE-SD 